\title{
EVALUATION OF REMINERALIZATION OF GRAPE SEED EXTRACT VERSUS SODIUM FLUORIDE ON DEMINERALIZED PRIMARY ANTERIOR TEETH: AN IN-VITRO STUDY
}

\author{
Riham A. Amin*, Samah M. Awad** and Essam A. Abd El Sattar***
}

\begin{abstract}
Background and aims: Enhancing remineralization is the main goal of clinical prevention of caries lesion. The present in vitro study aimed to assess the remineralizing effect of grape seed extract (GSE) versus sodium fluoride on demineralized primary anterior teeth.

Materials and Methods: An in vitro study was carried out on 56 human sound primary anterior teeth (incisors and canines). Teeth fragments were divided into two groups according to the following treatments: GSE (Grape seed extract) represented the case group; $\mathrm{NaF}$ (Sodium fluoride $1000 \mathrm{ppm}$ ) represented the control group. Teeth were subjected to six daily $\mathrm{pH}$ cycles for eight days. Within the daily cycling, the specimens were kept in buffered solution at $37^{\circ} \mathrm{C}$. The samples were evaluated using a scanning electron microscope and a micro-hardness tester.
\end{abstract}

Results: Data were analyzed using Student's t-test ( $p<0.001)$. The mean surface microhardness for GSE group was 40 (VHN) and for NaF group was 59.2 (VHN). Grape seed extract showed statistically significantly lower mean micro-hardness than Sodium Fluoride. Regarding enamel remineralization, the SEM data of the GSE treated group had revealed deposits of spherical insoluble complexes precipitation on the remineralized surface.

Conclusion: Based on the data obtained in this in vitro study, it is suggested that grape seed extract promote remineralization of artificial dentin carious lesions in but in a lower scale when compared to sodium fluoride. GSE enhanced the remineralization process of artificial enamel lesions of primary teeth, and thus, might be considered an effective natural agent in treatment of early enamel carious lesions.

KEYWORDS: Primary teeth, Enamel remineralization, Grape seed extract, Proanthocyanidin, Sodium fluoride, Demineralization, Dentin

\footnotetext{
* Dentist at Ministry of Health, Cairo, Egypt.

** Associate Prof. of Pediatric Dentistry and Dental Public Health, Faculty of Dentistry, Cairo University, Egypt. *** Prof. of Pharmacognosy, Faculty of Pharmacy, Cairo University, Egypt.
} 


\section{INTRODUCTION}

Dental caries is a highly prevalent disease and a constant problem in public health. ${ }^{10}$ The acidproducing bacteria in the dental plaque (biofilm) metabolize dietary carbohydrates producing weak acids. This causes the local $\mathrm{pH}$ to fall below a critical value. The fall in the $\mathrm{pH}$ allows the mineral component of the tooth (hydroxyapatite) to dissolve releasing calcium and phosphate ions. This process is known as demineralization . ${ }^{1}$

White spot lesion is the earliest clinical sign of dental caries, characterized by subsurface enamel demineralization. When the $\mathrm{pH}$ increases, some minerals can be re-precipitated by diffusion of calcium and phosphate ions from the saliva back into the porous surface created by mineral loss. This is known as remineralization process . ${ }^{1}$

Many components that are naturally present in regular diet have been shown to promote health and reduce risk for many common diseases. It is believed that antimicrobial compounds of plant origin can serve as alternatives to the commonly used chemical types for controlling dental plaque and dental diseases. ${ }^{14,10}$

Grape seed extract (GSE) is a rich source of proanthocyanidin (PA), mainly composed of monomeric catechin and epicatechin, gallic acid and polymeric and oligomeric procyanidins. ${ }^{8}$

Proanthocyanidin (PA) has been proved to strengthen collagen-based tissues by increasing collagen cross-links. It is claimed that it can increase collagen synthesis and accelerates the conversion of soluble collagen into insoluble collagen. Proanthocyanidin has proved safe in different clinical applications and has been used as dietary supplements as well. ${ }^{8}$

\section{MATERIALS AND METHODS}

The present study was carried out at Faculty of Dentistry and Faculty of Pharmacy, Cairo University, Egypt.

\section{MATERIALS}

The grape seeds utilized in this study were obtained from the Agriculture Research Centre in the form of seeds. Sodium fluoride (1000 ppm) was prepared and adopted as a control group. The Buffering solution was of $\mathrm{pH}$ (7) and the demineralizing solution was of $\mathrm{pH}$ (5). Acid resistant nail varnish was used to cover sectioned teeth surfaces.

\section{METHODS}

\section{Teeth selection and preparation}

Teeth selected for the study were extracted primary sound anterior teeth (incisors and canines). All teeth had been cleaned by $0.5 \%$ chloramin solution and immersed in distilled water. ${ }^{8}$ Teeth were mounted in light-curing acrylic resin. They were sectioned mesiodistally by low speed diamond saw cooled by water. The sectioned surfaces were covered with acid resistant nail varnish. The slices were stored at $4{ }^{\circ} \mathrm{C}$ prior to use. ${ }^{8}$

\section{Preparation of solutions:}

The Demineralizing solution was formed of (2.25 mM CaCl $2.2 \mathrm{H}_{2} \mathrm{O}, 1.35 \mathrm{mM} \mathrm{KH_{2 }} \mathrm{PO}_{4}, 130 \mathrm{mM}$ $\mathrm{KCl}, 50 \mathrm{mM}$ acetic acid) and the buffering solution was formed of $(2.25 \mathrm{mM} \mathrm{CaCl} 2.2 \mathrm{H} 2 \mathrm{O}, 1.35 \mathrm{mM}$ $\mathrm{KH}_{2} \mathrm{PO}_{4}, 130 \mathrm{mM} \mathrm{KCl}, 20 \mathrm{mM}$ HEPES $) .{ }^{10}$ Solutions were prepared in the laboratory of Pharmacognosy department, Faculty of Pharmacy, Cairo University.

\section{Preparation of Grape Seed Extract (GSE):}

The preparation was done at the Pharmacognosy laboratory, Faculty of Pharmacy.

The grape seeds were obtained from Agriculture Research Center, in the form of seeds and ground into a powder to be ready for extraction. The powdered grape seeds $(300 \mathrm{~g})$ were extracted with ethanolwater mixture in ratio of 70:30, v/v $(500 \mathrm{ml})$, by maceration method. ${ }^{8}$ The powder was macerated 
for three or more days. It was homogenized using homogenizer frequently until complete extraction of plant material occurred. Later, the material was strained and the remaining solid was squeezed to remove all the remaining solvent. The combined extract was filtered, concentrated and the solvent evaporated under reduced pressure. ${ }^{5}$

\section{Determination of Total Phenol Content}

By Folin-Ciocalteu method in which a mixture of phosphomolybdate and phosphotungstate for the colorimetric in vitro assay of phynolic and polyphenolic antioxidants was obtained. One $\mathrm{mL}$ of GSE solution in aceton/water $(6 \mathrm{ml} / 4 \mathrm{ml})$ was transferred to test tube and mixed with $0.2 \mathrm{~mL}$ of Folin-Ciocalteu reagent. After mixing for $3 \mathrm{~min}$, $1 \mathrm{~mL}$ of $2 \%$ sodium carbonate was added. The mixture was agitated with vortex mixer and kept in dark for $30 \mathrm{~min}$, after which they were centrifuged at $12000 \mathrm{~g}$ for $5 \mathrm{~min}$. The absorbance of the extracts and a prepared blank were measured at $750 \mathrm{~nm}$ using spectrophotometer. The measurements were compared to standard curve of prepared Gallic acid solution and expressed as grams of Gallic acid equivalents (GAE) per 100 grams of the extract, which was determined from known concentrations of gallic acid standard prepared similarly.

Concentration of phenols in Grape seed was $(50 \mathrm{mg} / 1 \mathrm{~g}$ extract).

\section{Determination of total proanthocyanidin}

Condensed tannins (proanthocyanidins) were determined according to the method of Sun et al. 1998. To $50 \mu$ L of diluted sample, $3 \mathrm{~mL}$ of $4 \%$ vanillin solution in methanol and $1.5 \mathrm{~mL}$ of concentrated $\mathrm{HCl}$ were added. The mixture was allowed to stand for $15 \mathrm{~min}$, and absorption was measured at $500 \mathrm{~nm}$ against methanol as a blank. The amount of total condensed tannins was expressed as mg (+)-catechin/g extract. All samples were analyzed in triplicate. ${ }^{12}$ Standard calibration curve of catechin was constructed using five dilutions between 25 -
$1000 \mu \mathrm{g} / \mathrm{ml}$ using the same procedure of the tested sample.

The total proanthocyanidins content of the ethanolic extract was determined from the standard curve as $686.916 \pm 0.14 \mathrm{mg}$ catechin/ $1 \mathrm{~g}$ extract.

\section{- Grouping of samples:}

\section{Sequence generation:}

Teeth were randomly assigned to either control or case group with a 1:1 allocation as per a computer generated randomization schedule. The GSE represent the case group and the $\mathrm{NaF}$ represented the control group.

\section{- pH cycling (Treatment/Demineralization/Rem- ineralization)}

The samples were subjected to $\mathrm{pH}$-cycling (demineralization and remineralization) in conjunction with the treatments according to the groups. Initially, the fragments were placed in $50 \mathrm{ml}$ of treatment solution (GSE, NaF) for 10 minutes, then in $50 \mathrm{ml}$ of demineralizing solution for 30 minutes and finally in $50 \mathrm{ml}$ of buffered solution for 10 minutes. These $\mathrm{pH}$ cycles/treatments were performed 6 times a day for 8 days. Between the treatment and $\mathrm{pH}$ cycling, the specimens were washed thoroughly with distilled water. Between the daily cycling, the specimens were stored in buffered solution at $37^{\circ} \mathrm{C}$.

\section{Post-treatment analysis}

After pH-cycling, samples were washed with deionized water. Fifty four out of fifty six specimens of each group were subjected to microhardness test and the remaining teeth samples were used for scanning electron microscope analysis

\section{A-Microhardness test}

Fifty four specimens from group A and group $B$ were rinsed with deionized water, embedded in epoxy resin, grounded with water-cooled discs and 
polished with 1-microm $\mathrm{Al}_{2} \mathrm{O}_{3}$ felt papers. Surface micro-hardness was measured by a micro hardness tester under a load of $50 \mathrm{gr} / 10 \mathrm{~s} .{ }^{8}$

Three indentations were done on each specimen and the average values were calculated. Then the average values for both groups were compared by independent t- test .8

\section{B-Scanning electron microscope (SEM)}

The two remaining samples of each group were dried with minimum of $0.5 \mathrm{~cm}$ in thickness and were gold coated for scanning electron microscope evaluation. ${ }^{8}$ The enamel morphology of demineralized teeth was inspected.

\section{Energy Dispersive X-Ray Analyzer (EDX or EDA)}

An analytical technique was used in the present study in conjunction with SEM analysis to provide elemental identification and quantitative compositional information for the deposited mineral particles.

\section{Statistical method}

Data were presented as mean, median, standard deviation (SD), minimum, maximum and 95\% Confidence Interval $(95 \% \mathrm{CI})$ for the mean values. Data were explored for normality by checking the data distribution and using Kolmogorov-Smirnov and Shapiro-Wilk tests. Micro-hardness data showed normal (parametric) distribution. Student's t-test was used to compare between the two groups. The significance level was set at $\mathrm{P} \leq 0.05$. Statistical analysis was performed with IBM ${ }^{\circledR}$ SPSS ${ }^{\circledR}$ Statistics Version 20 for Windows.

\section{RESULTS}

Table (1) demonstrates the mean micro-hardness values $( \pm \mathrm{SD})$ of the two groups. Student's-test revealed statistically significant differences between the two groups Figure (1). Samples treated with GSE had significantly lower micro-hardness values compared with the control group $\mathrm{NaF}$.

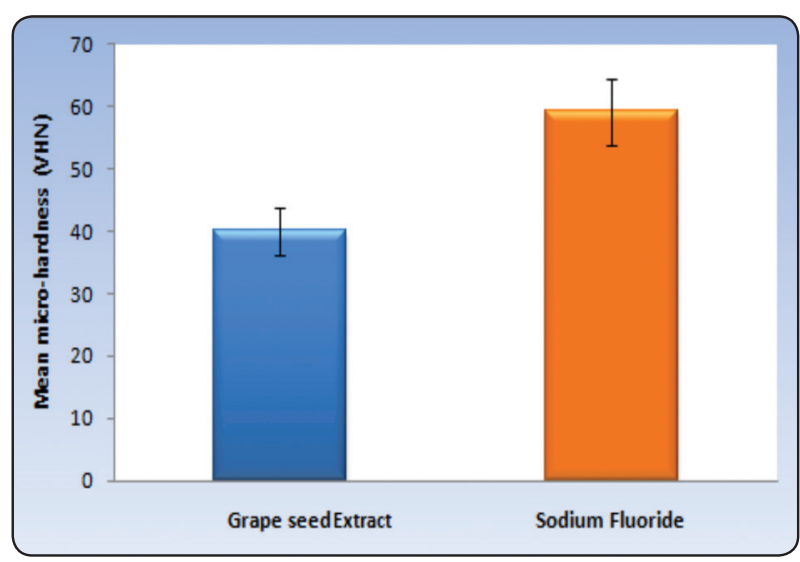

Fig. (1): Mean values for micro-hardness of the two studied groups.

\section{Scanning electron microscope (SEM) analysis}

Figure (2): showed the SEM photomicrograph of untreated sound enamel $(\times 2000$ magnification $)$ for both groups, revealing an orderly smooth appearance. There were also some spherical particles on the surface.

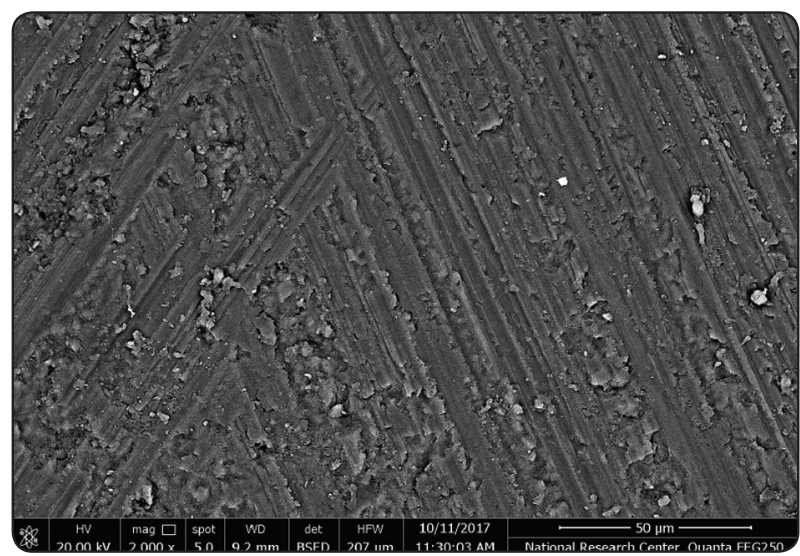

Fig. (2): Scanning Electron Microscope photograph of untreated sound enamel.

Figure (3): showed the photomicrograph of demineralized enamel $(\times 2000$ magnification $)$ before treatment; the enamel surface was rough and disorganized with significant porosities. 


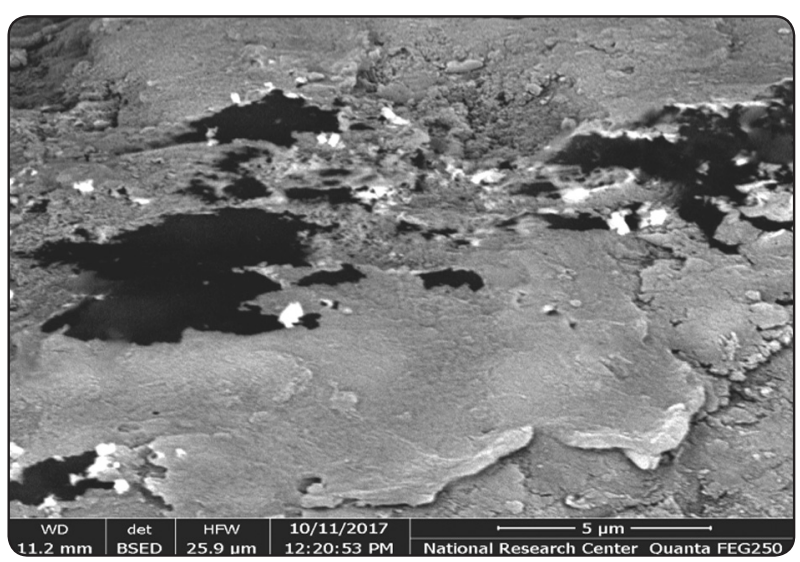

Fig. (3): Scanning Electron Microscope photomicrograph of demineralized lesions.

\section{- Effect of GSE versus NaF on Enamel remin- eralization after $\mathbf{p H}$ cycling.}

Figure (4) showed the demineralized enamel exposed to GSE ( $\times 2000$ magnification) there were some coating depositions of some insoluble complexes on the enamel surface. The reaction products of GSE were seen as amorphous clumps. Spherical globular agglomerates were observed on the surface of the enamel, with different sizes. Some crystals were adherent to each other and precipitated on the demineralized areas.

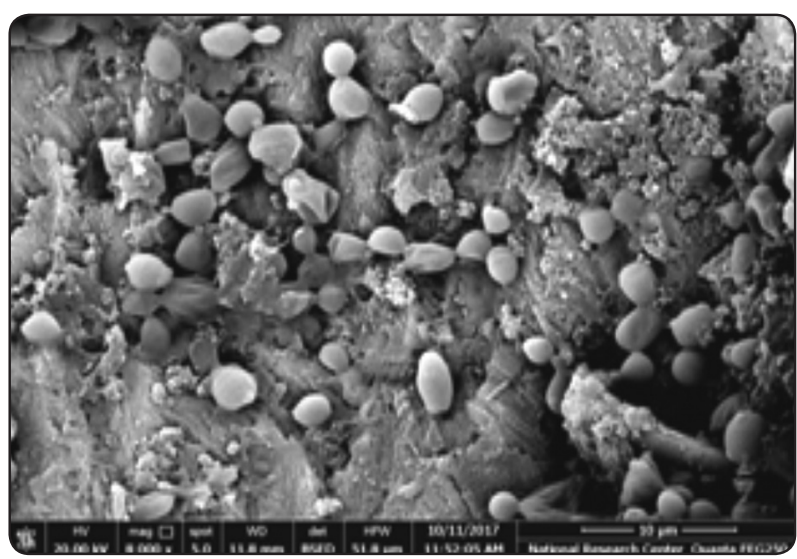

Fig. (4): Photomicrograph of remineralized lesions with grape seed extract.
Figure 5: Showed the SEM Edax for the spherical particles. The graph revealed analytic description for the main components of the spherical particles deposited within the remineralized lesions in group A. The spherical was composed of calcium, phosphate, carbon and oxygen. The two highest elements were calcium $(\mathrm{Ca})$ and phosphate $(\mathrm{Ph})$.

\section{- Effect of NaF on enamel remineralization:}

Figure (6): showed the remineralized enamel with sodium fluoride $(\mathrm{NaF})$. Enamel surface revealed many calcific deposits of fluoroapatite covering the demineralized areas $(\times 2000$ magnification).

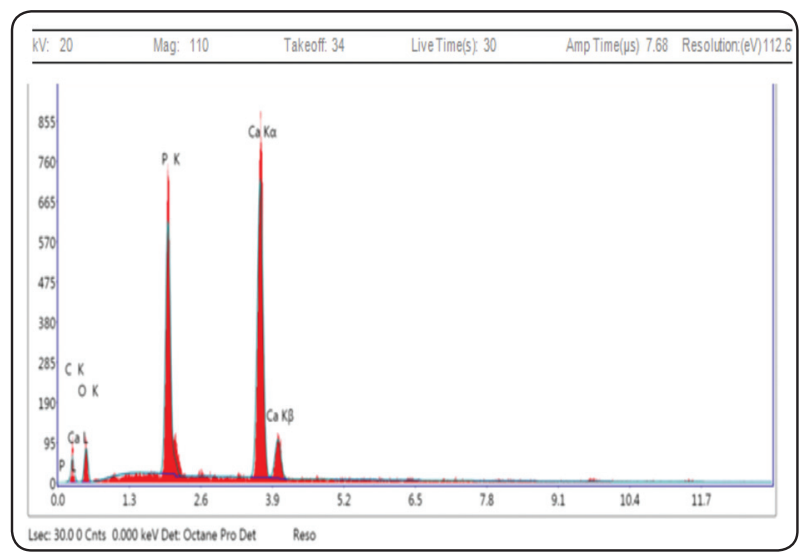

Fig. (5): Scanning Electron Microscope Edax analysis for calcific crystals formed in GSE treated samples.

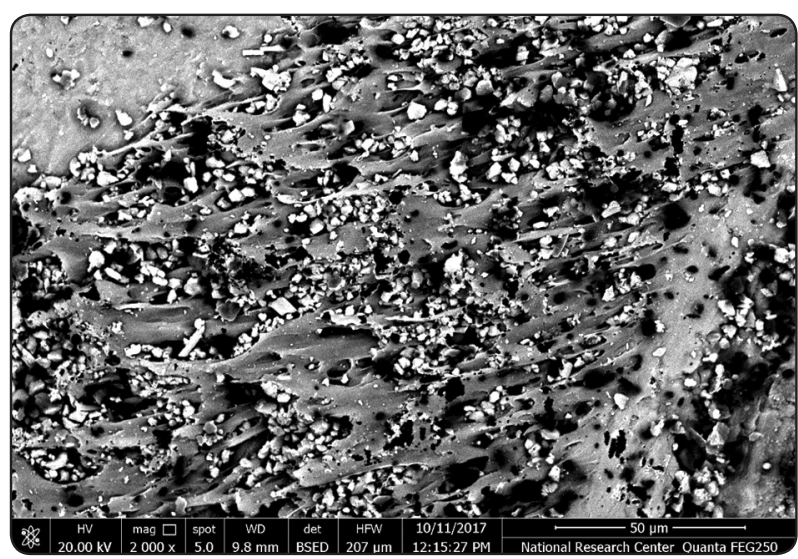

Fig. (6): Photomicrograph of remineralized lesions by fluoride (fluoroapatite).Multiple crystals deposited within the dark spaces. 
TABLE (I) Descriptive statistics and results of micro-hardness values of the two groups.

\begin{tabular}{|c|c|c|c|c|c|c|c|c|}
\hline \multirow[b]{2}{*}{ Group } & \multirow{2}{*}{ Mean } & \multirow{2}{*}{ SD } & \multirow{2}{*}{ Median } & \multirow{2}{*}{ Minimum } & \multirow{2}{*}{ Maximum } & \multicolumn{2}{|c|}{$95 \% \mathrm{Cl}$} & \multirow{2}{*}{$P$-value } \\
\hline & & & & & & $\begin{array}{l}\text { Lower } \\
\text { bound }\end{array}$ & $\begin{array}{l}\text { Upper } \\
\text { bound }\end{array}$ & \\
\hline $\begin{array}{l}\text { Grape seed } \\
\text { extract }\end{array}$ & 40.0 & 3.8 & 40.4 & 32.3 & 48.4 & 39.0 & 41.1 & \multirow{2}{*}{$<0.001 *$} \\
\hline $\begin{array}{l}\text { Sodium } \\
\text { Fluoride }\end{array}$ & 59.2 & 5.3 & 59.1 & 43.2 & 72.6 & 57.8 & 60.7 & \\
\hline
\end{tabular}

\section{*: Significant at $P \leq 0.05$}

\section{DISCUSSION}

Natural products had been the focus of many researches, to be used as new therapeutic agents. Grape seed extract is a natural product that is currently used for different therapeutic purposes and subjected to various studies. This depends on its claimed significant anti-oxidant, anti-bacterial, antiinflammatory and free radical scavenger property ${ }^{8}$

The concept of minimally invasive dentistry via remineralization of demineralized tooth structure is of great significance; to preserve the remaining tooth structure. Remineralization is a process whereby calcium and phosphate ions are supplied from an external source to the tooth, leading to ion deposition into crystal voids in demineralized enamel, thus producing net mineral gain . ${ }^{3}$

The study aimed to evaluate remineralization effect of grape seed extract compared with sodium fluoride on demineralized enamel and dentin in primary teeth. The research adopted alternative hypothesis and assumed that there was difference between grape seed extract and sodium fluoride on the surface micro-hardness of demineralized enamel and dentin surfaces.
In order to detect the remineralizing effect on carious teeth; sound primary anterior teeth with artificial carious lesion had been used.Sodium fluoride in the current study was used as a positive control, particularly at $1000 \mathrm{ppm}$ in a solution form.

The grape seed extract used in this study was rich in PA. The total PA content was $686.916 \pm 0.14$ mg catechin equivalent/ $1 \mathrm{~g}$ extract, determined according to a special method proposed by Sun et al., 1998. The PA is commonly used as natural antioxidants, free radical scavengers and allows for absorption of calcium. It has the potential to give rise to stable hydrogen, and generate non-biodegradable collagen matrices. ${ }^{10}$ For these characteristics, GSE has been investigated in the remineralization process of teeth.

The GSE had been prepared through a special method proposed by Mirkarimi et al., 2013. The seeds were obtained and prepared to obtain the extract. The $\mathrm{pH}$ cycling method was used to mimic natural dynamic changes occurring within oral cavity relating to demineralization and remineralization process. The cycle involved immersion of the prepared teeth in the treatment solutions followed by immersion in the demineralizing and buffering 
solutions sequentially. Each group was assigned separately to its cycle six times daily for eight days.

After $\mathrm{pH}$ cycling both groups had been subjected to post treatment analysis including microhardness test and scanning electron microscope. According to the results obtained from microhardness test, regarding dentin remineralizarion, the alternative hypothesis was accepted.

The results of the current study showed that grape seed extract was able to induce remineralization with a mean micro-hardness about 40 (VHN). However, samples treated with sodium fluoride solution showed a mean microhardness of 59.2 $(\mathrm{VHN})(\mathrm{p}<0.001)$. These results were in contrast to results published by Xie et al., $\mathbf{2 0 0 8}$ where there was no statistically significant difference between the fluoride and grape seed treated groups. This might be due to differences in used samples where Xie et al., 2008 had employed root fragments in their study. This might have created direct interaction with the organic portion of the root dentin by the PA-collagen interaction, thus stabilizing the exposed collagen matrix. This had resulted in increasing in dentin mechanical properties.

The remineralizing effect of GSE appears to be lower than that of $\mathrm{NaF}$ owing to the variation in molecular size of PA content of the used extract. A possibility is that the behavior of PA molecular size may have played a role. The effect of PA may be confined to the superficial layer due to probability of high molecular weight of PA molecules and thus they could not penetrate deep into the underlying layers. In fact, PA contributed to mineral deposition on the lesion surface only, which inhibited further mineral deposition in the deeper part of the lesion ${ }^{4}$

Another possible cause is that seasonal fluctuations may affect the availability of active ingredients within medical plants (GSE) and therefore affects their therapeutic efficacy. ${ }^{11}$ Thus the effect of PA containing GSE used in the study would be different from that used in the reported studies. According to Liu et al., 2015, changes in ecological factors in different areas affect contents and proportions of the active substances produced by plants. Also, environmental variations may also play a role in chemical modulations for plant active constituents. ${ }^{9}$ Therefore, for these possible reasons might possibly lead to the variation in the GSE efficacy.

Based on the data obtained from SEM analysis regarding enamel remineralization, the alternative hypothesis was rejected. Grape seed extract exposed enamel surface showed high remineralizing effect like that in sodium fluoride treated group. The SEM was used as a qualitative measure. The analysis of enamel surface in GSE treated group showed the precipitation of insoluble spherical particles with different sizes within the artificial lesions. Some particles aggregated to form complexes. This was in agreement with SEM results reported by Mirkarimi et al., 2013 and Tang et al., 2013, where enamel surface showed multiple spherical deposits of calcific particles after treatment with grape seed extract. This may be due to the precipitation of minerals, especially in its interior, since most of its structure is composed of inorganic matter.

Further, this could be explained by presence of gallic acid (one of the major constituents of grape seed extract) and Gallachinensis which facilitated the mineral deposition, predominately on the surface layer. Also, PA has a chelating mechanism with calcium ions, which enhances mineral deposition on the surface ${ }^{2,4}$

It was found that type $\mathrm{X}$ collagen was one of the candidate molecules present in the enamel matrix. This might have been involved in mineralization of enamel as well. This explained the presence of the collagen cross-links produced by the positive effects of remineralization of enamel defects by GSE. As the presence of the terminal carboxyl groups and amine groups mainly contribute to the absorption of collagen peptides to the hydroxyapatite surfaces. In addition, the $-\mathrm{OH}$ and positively charged $\mathrm{NH}^{+}$groups of peptides in particular bind to the 
surfaces. As a result, their presence should therefore promote hydroxyapatite growth. Henceforth, collagen might have served as a substrate for apatite formation.$^{8}$

In the current study, the SEM Edax technique was used to analyze the nature of deposited particles. It was reported that the major elements forming these particles were calcium, phosphate, carbon and oxygen. The presence of carbon ions might have acted as a good indicator for sharing of GSE in the remineralization process

\section{CONCLUSION}

Considering the results of this in vitro study, Grape seed extract was considered less effective than sodium fluoride regarding dentin remineralization. However, it can be assumed that Grape seed extract might serve as a promising natural alternative for treatment of early enamel carious lesions.

\section{ACKNOWLEDGMENT}

The author wishes to thank the National Research Centre and Oral Histology Department, Faculty of dentistry, Cairo University for the support.

\section{REFERENCES}

1. Bansal, K., Balhara, N., \&Marwaha, M. (2014). Remineralizing efficacy of CalcareaFluorica tablets on the artificial carious enamel lesions using scanning electron microscope and surface microhardness testing: In vivo study. Indian Journal of Dental Research, 25(6), 777-782.

2. Cheng, L., Li, J., Hao, Y., \& Zhou, X. (2010). Effect of compounds of Gallachinensis on remineralization of enamel surface in vitro. Archives of oral biology, 55(6), 435-440.

3. Jawale, K. D., Kamat, S. B., Patil, J. A., Nanjannawar, G. S., \& Chopade, R. V. (2017). Grape seed extract: An innovation in remineralization. Journal of Conservative Dentistry, 20(6), 415-418.

4. Khamverdi, Z., Kordestani, M., \&Soltanian, A. R. (2017). Effect of Proanthocyanidin, Fluoride and Casein Phosphopeptide Amorphous Calcium Phosphate Remineralizing Agents on Microhardness of Demineralized Dentin. Journal of dentistry (Tehran, Iran), 14(2), 76-83.
5. Khan, B. A., Akhtar, N., Rasul, A., Mahmood, T., Khan, H. S., Iqbal, M., \&Murtaza, G. (2012). Investigation of the effects of extraction solvent/technique on the antioxidant activity of Cassia fistula L. Journal of Medicinal Plants Research, 6(3), 500-503.

6. Liu, W., Liu, J., Yin, D., \& Zhao, X. (2015). Influence of ecological factors on the production of active substances in the anti-cancer plant Sinopodophyllumhexandrum (Royle) TS Ying. PLoS one, 10(4), e0122981. URL: https://www. ncbi.nlm.nih.gov/pmc/articles/PMC4398539/

7. Medini, F., Fellah, H., Ksouri, R., \&Abdelly, C. (2014) Total phenolic, flavonoid and tannin contents and antioxidant and antimicrobial activities of organic extracts of shoots of the plant Limoniumdelicatulum. Journal of Taibah University for science, 8(3), 216-224

8. Mirkarimi, M., Eskandarion, S., Bargrizan, M., Delazar, A., \&Kharazifard, M. J. (2013). Remineralization of artificial caries in primary teeth by grape seed extract: an in vitro study. Journal of dental research, dental clinics, dental prospects, 7(4), 206-210.

9. Moore, B. D., Andrew, R. L., Külheim, C., \& Foley, W. J. (2014). Explaining intraspecific diversity in plant secondary metabolites in an ecological context. New Phytologist, 201(3), 733-750. URL: http://onlinelibrary.wiley. com/doi/10.1111/nph.12526/pdf.

10. Silva, A. P. P. D., Gonçalves, R. S., Borges, A. F. S., Bedran-Russo, A. K., \& Shinohara, M. S. (2015). Effectiveness of plant-derived proanthocyanidins on demineralization on enamel and dentin under artificial cariogenic challenge. Journal of Applied Oral Science, 23(3), 302-309.

11. Soni, U., Brar, S., \&Gauttam, V. K. (2015). Effect of seasonal variation on secondary metabolites of medicinal plants. International Journal of Pharmaceutical Sciences and Research, 6(9), 3654. URL:http://ijpsr.com/bft-article/ effect-of-seasonal-variation-on-secondarymetabolites-ofmedicinal-plants $/$ view=fulltext .

12. Sun, B., Ricardo-da-Silva, J. M., \&Spranger, I. (1998). Critical factors of vanillin assay for catechins and proanthocyanidins. Journal of Agricultural and Food Chemistry, 46(10), 4267-4274.

13. Tang, C. F., Fang, M., Liu, R. R., Dou, Q., Chai, Z. G., Xiao, Y. H., \& Chen, J. H. (2013). The role of grape seed extract in the remineralization of demineralized dentine: micromorphological and physical analyses. Archives of oral biology, 58(12), 1769-1776.

14. Wu, C. D. (2009). Grape products and oral health. The Journal of nutrition, 139(9), 1818S-1823S

15. Xie, Q., Bedran-Russo, A. K., \& Wu, C. D. (2008). In vitro remineralization effects of grape seed extract on artificial root caries. Journal of dentistry, 36(11), 900-906. 